\title{
A LOW-COST RESISTIVIMETER FOR USE IN PRACTICAL LECTURES OF APPLIED GEOPHYSICS
}

\author{
Walter Sydney Dutra Folly and Aracy Sousa Senra
}

\begin{abstract}
We describe the construction and testing of a simple and efficient low-cost resistivimeter designed for use in practical classes in Applied Geophysics. The equipment was successfully tested in a vertical electrical sounding (VES) performed on sandy terrain within the campus of the Universidade Federal de Sergipe, Brazil. The VES results were in good agreement with the profiles obtained from two boreholes located approximately $500 \mathrm{~m}$ from the test area, clearly demonstrating the efficiency of the equipment and the adopted methodology.
\end{abstract}

Keywords: vertical electrical sounding, electrical resistivity, resistivity profile.

RESUMO. Neste artigo, descrevemos a construção e o teste de um resistivímetro de baixo custo, simples e eficiente, concebido para ser utilizado em aulas práticas de Geofísica Aplicada. 0 equipamento foi testado com a realização de uma sondagem elétrica vertical (SEV) em um terreno arenoso localizado no campus da Universidade Federal de Sergipe, Brasil. Os resultados obtidos nesta SEV apresentaram boa concordância com os perfis observados em dois poços de sondagem localizados a $500 \mathrm{~m}$ da área de teste, fato que comprovou a eficiência do equipamento e da metodologia adotada.

Palavras-chave: sondagem elétrica vertical, resistividade elétrica, perfil de resistividade. 


\section{INTRODUCTION}

Electrical resistivity surveys have been used for a wide variety of purposes, such as mapping of industrial waste plumes (Rucker et al., 2010), environmental monitoring (Rucker et al., 2011), imaging of geological faults (Nguyen et al., 2005), delineation of volcanic ash bodies (Xia et al., 2010) and hydrogeological surveys (Cutrim et al., 2007; Cutrim \& Shiraiwa, 2011). The broad applicability of this geophysical method is partly due to recent advances in mathematical modeling and computational resources, which allow rapid 2D or 3D data analyses and quick inversion of the resistivity pseudosections. Paralleling these advances, Applied Geophysics classes taught to students of Geology and other undergraduate courses around the world have progressively increased the time devoted to this geophysical method, often with the inclusion of practical classes. In addition to technical advances in data analysis, digital resistivimeters for scientific research also evolved. However, state-of-the-art resistivimeters can be prohibitively expensive for in-field instructional purposes, especially when such activities involve a large number of students.

Here, we describe the construction and preliminary testing of a simple but efficient resistivimeter, specifically designed for use in practical classes in Applied Geophysics. The device was designed to cover a wide range of apparent resistivity and facilitate the explanation of the physical concepts involved in its use.

\section{METHODOLOGY}

\section{Basic circuitry}

The basic resistivimeter consists of a voltmeter, an ammeter (we used low-cost multimeters Foxlux FX-MD, 3-1/2 digit LCD) and a power supply able to furnish a wide range of output voltages. The output polarity of the power supply must also be invertible, to allow the cancelling of possible effects of telluric currents flowing in the ground during the measurement process. Soils and rocks under analysis often present relatively low values of apparent resistivity. In such cases, a low voltage (a few volts) is sufficient to produce a reasonable current across them. On the other hand, in the case of less permeable rocks, the apparent resistivity can achieve several thousands of $\Omega \mathrm{m}$. Thus, higher voltages are required to produce current values easily readable on the ammeter. Our resistivimeter works in three different ranges (modes) of open-circuit output voltage (see schematic in Fig. 1). In the low resistivity mode (LowRes), the open-circuit output voltage is equal the input voltage, which is furnished by an automotive battery (12V). This mode allows the measurement of a low apparent resistivity (as occurs in clayey soils or sandy soils saturated with seawater). For measurements of intermediary or high values of resistivity, the maximum open-circuit output voltage can be chosen within the ranges of 150VDC (LV mode) or 560VDC (HV mode). This choice is made by adjusting the selector switch $\mathrm{S} 1$ (single-pole inverter).

In order to obtain the high voltage necessary to operate in the HV mode, we used an automotive-type power inverter (12VDC to $110 \mathrm{VAC} / 60 \mathrm{~Hz}$ or similar) connected to a voltage multiplier circuit formed by the diodes D1, D2, D3 and D4 (1N4007) and the electrolytic capacitors C1, C2, C3 and C4 (100 $\mu$ F; 250V) (Figs. 1 and 2a). While the power inverter converts the 12VDC from the battery to $110 \mathrm{VAC} / 60 \mathrm{~Hz}$, the voltage multiplier circuit converts the obtained 110VAC into a DC voltage of approximately 560V. In the LV mode, the voltage multiplier is not used and the output voltage is obtained from the half-wave rectifier composed by D1 and C1. To avoid damage to the diodes by current surges, a limiting resistor $(100 \Omega ; 10 \mathrm{~W})$ was installed in series with the output of the power inverter. For both $\mathrm{LV}$ and $\mathrm{HV}$ modes, the current applied to the soil can be controlled by a potentiometer ( $47 \mathrm{k} \Omega$ linear) connected to the gate of the field-effect transistor (T1) (MOSFET type IRF740 or equivalent). It is very important to remark that $\mathrm{T} 1$ should be fitted to a heat sink with a total area of at least 100 square centimeters. The reference voltage on this potentiometer is defined by the rectifier diode D5 (1N4007), the $68 \mathrm{k} \Omega$ resistor, the zener diode D6 (10V; 1W) and the electrolytic capacitor C5 (470 $\mathrm{F} ; 50 \mathrm{~V})$ (see Fig. 1).

The current applied to the soil during the measurement process can be inverted by adjusting switch S2 (bipolar inverter). This minimizes possible spurious potentials attributed to telluric currents flowing in the soil parallel to the electrodes line-up. Switch S3 (bipolar, 250V; 1A) controls the independent power supplies ( $9 \mathrm{~V}$ batteries) that feed the voltmeter and the ammeter. For any measurement mode, the current is applied to the soil only when the push-button PB1 (normally open, 250V; 5A) is depressed. This prevents the operator getting an electrical shock when handling the current electrodes. A wire resistor (6 $\Omega$; 20W) constrains the maximum output current to prevent it exceeding $2 \mathrm{~A}$ when the LowRes mode is selected. All electronic devices and connectors were mounted in an aluminum panel that acts as a mechanical chassis (Fig. 2a) for the circuitry. This panel was installed in a light ABS plastic case (Fig. 2b).

We use four stakes of copper-coated steel of about $30 \mathrm{~cm}$ length and $10 \mathrm{~mm}$ diameter as electrodes (see Fig. 3b). The stakes were cut from a rod normally used for electrical grounding in buildings and power lines - a material that is inexpensive and easy to find in electrical material stores. The connections between 


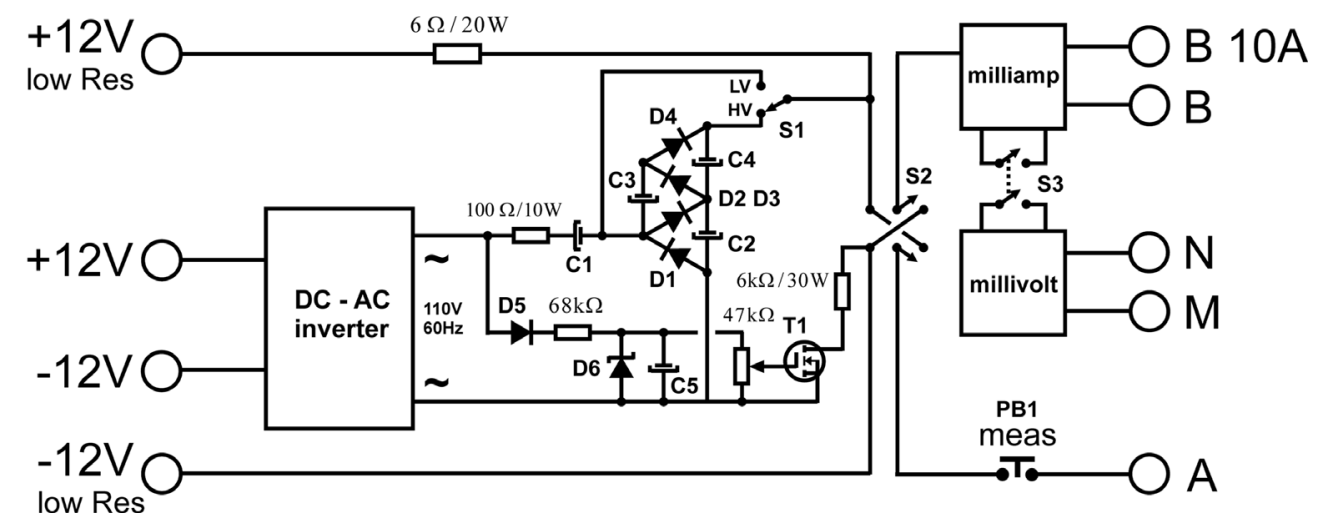

Figure 1 - Schematic diagram of the resistivimeter. Notice the DC-AC inverter and the voltage multiplier circuit formed by the diodes D1, D2, D3 and D4 and the capacitors C1, C2, C3 and C4.
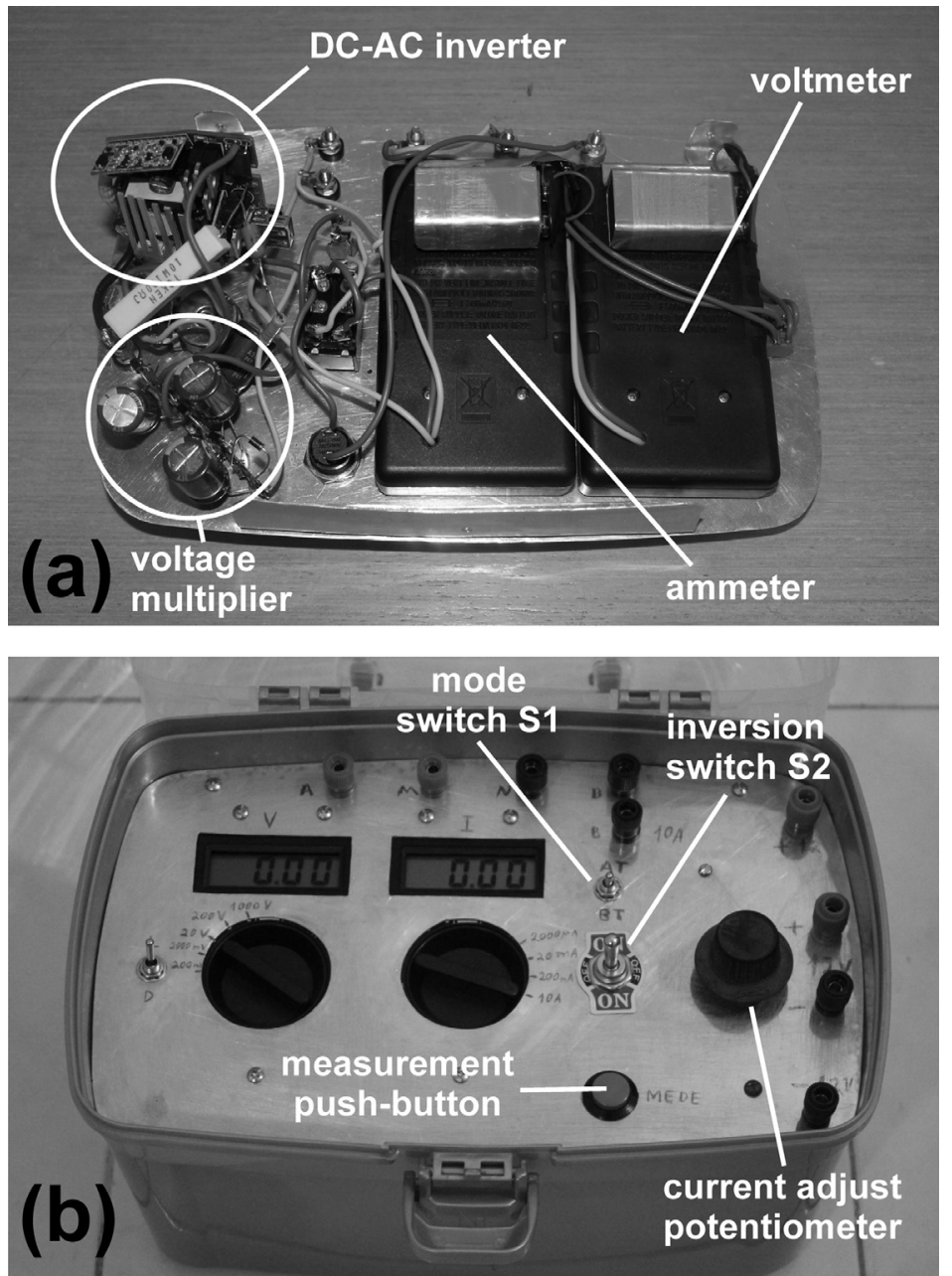

Figure 2 - The final arrangement of the main devices on the chassis (a). Notice the DC-AC inverter circuit, the voltage multiplier and the meters. The heat sink of $\mathrm{T} 1$ was removed to allow a better view of the other components. The plastic case of the resistivimeter and its main controls and switches are shown in (b). 
each electrode and the resistivimeter were made with isolated copper cables (12AWG) provided with banana type connectors. When adopting the Wenner electrode configuration in a field survey, the user should keep in mind that the total length of a current cable needs to be about three times the total length of a voltage cable.
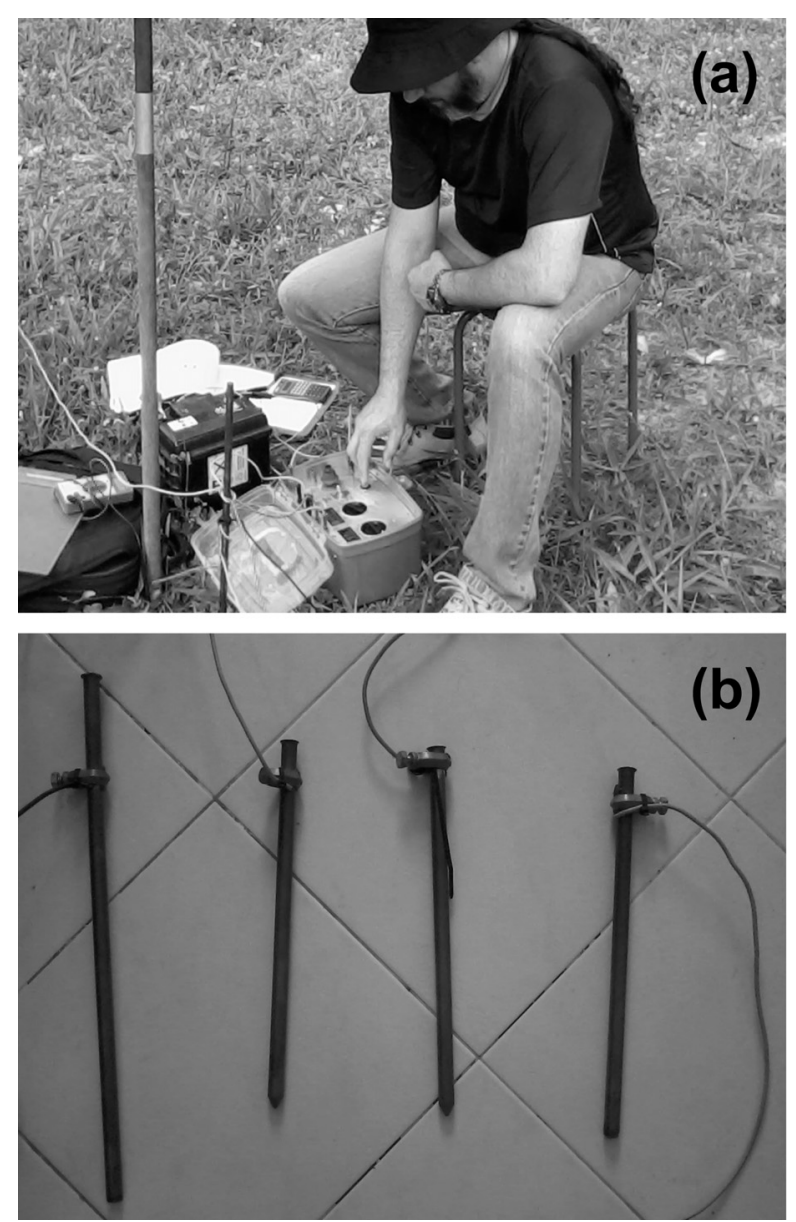

Figure 3 - (a) Field test of the resistivimeter with the performing of a VES in the test area. The test current is applied only when the measurement button is depressed. (b) The four copper-coated steel stakes used as electrodes.

\section{Measurement procedures}

The test of the equipment was performed in a single section of vertical electrical sounding (VES) employing the standard Wenner electrode configuration (A-M-N-B). This configuration was chosen due to its better sensitivity to vertical changes in apparent resistivity (Loke, 1999). If the penetration depth of the electrodes in the soil is negligible as compared with the interelectrode spacing $a$, the apparent resistivity $\rho_{a p}$ for a given value of $a$ is given by Equation (1) (Loke, 1999; Bhattacharya \& Patra, 1985). The correct alignment of the electrodes in the field, as well as the values of $a$, were controlled by using a measuring tape.

$$
\rho_{a p}=2 \pi a \frac{\Delta V}{I}
$$

In order to minimize the undesirable effects caused by natural currents flowing in the ground or even by contact potentials due to electrolytic reactions on the electrodes $\mathrm{M}$ and $\mathrm{N}$, the voltage $\Delta V$ and the measuring current $I$ were obtained from measurements carried out in the two different senses (inverted by means S2). By supposing a natural current $I_{\varepsilon}$ flowing in the ground parallel to the electrode line-up in the same sense of the applied current, we have:

$$
I_{+}=I+I_{\varepsilon}
$$

On the other hand, if the applied current is in the opposite sense of $I_{\varepsilon}$, we have,

$$
I_{-}=-I+I_{\varepsilon}
$$

where $I_{+}$and $I_{-}$are the readings of current in the direct $(+)$ and reverse (-) sense respectively. By subtracting Equation (3) from Equation (2), $I_{\varepsilon}$ is canceled, resulting in the following equation for the current $I$ :

$$
I=\frac{I_{+}-I_{-}}{2}
$$

Similarly, the presence of a resulting contact potential $V_{\varepsilon}$ on the electrodes $\mathrm{M}$ and $\mathrm{N}$ can be canceled by adopting an analogous procedure in which $\Delta V$ is given by the expression:

$$
\Delta V=\frac{\Delta V_{+}-\Delta V_{-}}{2}
$$

where $\Delta V_{+}$and $\Delta V_{-}$are the voltages observed when the measuring current is applied in the direct and reverse senses respectively.

\section{Test area}

A sandy terrain covered in grassy vegetation was chosen to test the resistivimeter (Fig. 3a). The test area belongs to the main campus of the Universidade Federal de Sergipe, Brazil and is I0cated near the university's central library.

The subsurface profile of the test area was inferred by continuity from the analysis of two boreholes located about $500 \mathrm{~m}$ from the test area (LTI Construções, 2013). The borehole profiles revealed the presence of fine-grained white sand at depths ranging up to $3.6 \mathrm{~m}$. Below this depth, the composition changes to a more compacted dark-yellow silty-sand containing quartz-rich gravel. These two boreholes were drilled using the percussion method 
with a $65 \mathrm{~kg}$ hammer (fall height of $75 \mathrm{~cm}$ ). Penetration of the perforation tool into the initial white sand layer required about 5 strokes/30 cm in comparison to about 25-35 strokes/30 cm for the compact dark-yellow sand layer. On average, the water table was at a depth of about $1.9 \mathrm{~m}$. The presence of roots and decomposing organic matter in the top layer was also recorded in the borehole profile.

\section{RESULTS}

The observed values of voltage $\Delta V$, current $I$ and apparent resistivity $\rho_{a p}$ with respect the electrode separation a are shown in Table 1 and Figure 4, which also shows the VES profile obtained by using the free software Res1D (Geotomo Software, 1995). For the Wenner configuration (A-M-N-B), the median investigation depth $z$ as a function of the electrode separation $a$ is given by Equation (6) and can be approximately considered as a half of $a$ (Loke, 1999). The values of resistivity, depth and thickness of the layers obtained from such inversion section are shown in Table 2.

$$
z=0,519 \cdot a
$$

Table 1 - Apparent resistivity for different values of voltage, current and electrode separation.

\begin{tabular}{|c|c|c|c|}
\hline$a(m)$ & $\Delta V(m V)$ & $I(m A)$ & $\rho_{a p}(\Omega \cdot m)$ \\
\hline 0.1 & 770.0 & 0.310 & 1560.66 \\
0.2 & 600.0 & 0.415 & 1816.83 \\
0.4 & 530.0 & 0.480 & 2775.07 \\
0.7 & 475.0 & 0.585 & 3571.21 \\
1.0 & 285.0 & 0.505 & 3545.96 \\
1.5 & 150.0 & 0.510 & 2771.99 \\
2.0 & 105.0 & 0.620 & 2128.18 \\
3.0 & 52.5 & 0.660 & 1499.40 \\
4.0 & 31.5 & 0.935 & 846.72 \\
5.0 & 10.0 & 0.695 & 452.03 \\
6.0 & 4.5 & 0.535 & 317.09 \\
7.0 & 2.0 & 0.370 & 237.74 \\
8.0 & 7.5 & 1.770 & 212.99 \\
9.0 & 5.0 & 1.545 & 183.01 \\
10.0 & 4.5 & 1.620 & 174.53 \\
\hline
\end{tabular}

\section{DISCUSSION}

The acquired voltage values (shown in Table 1) reveal a smooth decrease as electrode separation increases. At separation $a=$ $8 \mathrm{~m}$, it was necessary to readjust the excitation current in order to maintain the subsequent readings of voltage at a comfortable level above $2 \mathrm{mV}$. Although we initially applied inversion models with three and four layers, the best data fitting (RMS error of
4.84\%) was achieved with a five-layer model, which converged within 10 iterations.

Table 2 - Results obtained from the five-layer inversion model.

\begin{tabular}{|c|c|c|c|}
\hline $\begin{array}{c}\text { Layer } \\
\text { number }\end{array}$ & $\begin{array}{c}\text { Resistivity } \\
(\Omega \mathrm{m})\end{array}$ & $\begin{array}{c}\text { Depth } \\
(\mathrm{m})\end{array}$ & $\begin{array}{c}\text { Thickness } \\
(\mathrm{m})\end{array}$ \\
\hline 1 & 1433.40 & 0 & 0.20 \\
2 & 34221.98 & 0.20 & 0.08 \\
3 & 2051.15 & 0.28 & 1.63 \\
4 & 63.37 & 1.91 & 1.88 \\
5 & 207.08 & 3.79 & - \\
\hline
\end{tabular}

The first three layers observed in the test VES can be interpreted as corresponding to the unique first layer identified in the borehole profiles as white sand. Since the VES was performed in the morning, the topsoil at the time of the measurements was still humid from night dew. This factor combined with the presence of decomposing organic matter near the surface may explain the low resistivity in layer 1 in comparison to the layer just below. This humidity was almost certainly insufficient to reach the subsequent layers, and the sand in layer 2 remained very dry even during the night - explaining its high resistivity. In contrast, layer 3 is just above the water table and its water content is therefore probably higher than layer 2, a hypothesis that explains its moderately lower value for resistivity.

The lowest resistivity obtained from the VES profile ( $\rho=$ $63.37 \Omega \mathrm{m}$ ) indicates the presence of the water table at a depth of $1.91 \mathrm{~m}$ and, by extension, layer 4 can be interpreted as consisting of the same material as the layers above, but totally saturated with water. This result is concordant with the borehole profiles used as a reference (LTI Construções, 2013), in which the water table depth was in the range 1.7-2.1 $\mathrm{m}$, with an average value about $1.9 \mathrm{~m}$. Below the water table, the borehole profiles indicated the presence of a compact layer composed of a dark-yellow siltysand at depths ranging from 3.73-3.80 $\mathrm{m}$. The increase of resistivity observed in our VES profile at the depth of $3.79 \mathrm{~m}$ (layer 5 , $\rho=207.08 \Omega \mathrm{m}$ ) can be attributed to this material, which would necessarily have a lower water content due to its increased compactness.

In summary, there was a good agreement between the borehole profiles and the resistivity profile obtained by employing our resistivimeter. This fact indicates its satisfactory performance during the test.

\section{Safety rules}

As a high voltage may be present at the $A B$ terminals (about 150VDC in the LV mode or 560VDC in the HV mode), opera- 


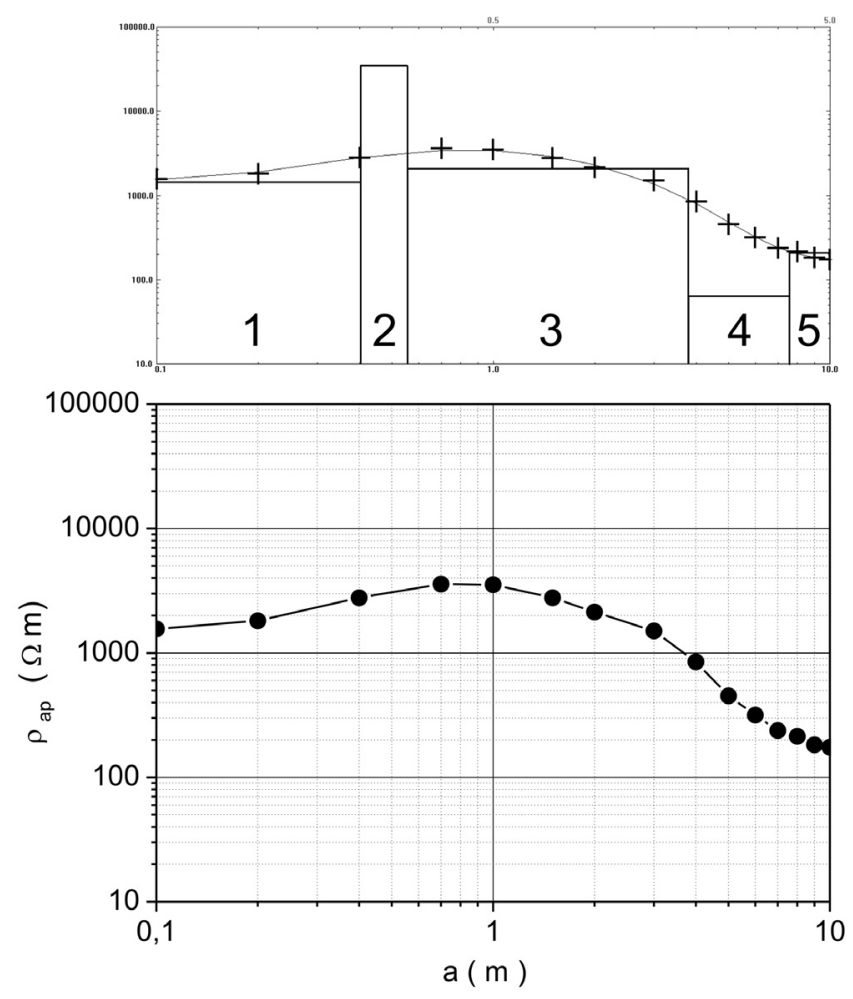

Figure 4 - Apparent resistivity for different electrode separation and interpretation of data by considering a five-layer model. The RMS error obtained for the fitted curve is $4.84 \%$.

tors of the device should strictly follow some safety rules to avoid the risk of electrical shock or damage the field-effect transistor $\mathrm{T1}$ and its peripheral components. Specifically, the operator should proceed as follows:

1) Never touch the AB terminals or the corresponding electrodes while the measurement button is depressed.

2) Always return the current potentiometer to its position of minimum after finish the measurements.

3) Never short-circuit the AB terminals or their electrodes in order to discharge the inner electrolytic capacitors. To do this, it is necessary to disconnect the battery cables and discharge the capacitors through the earth by depressing the measurement button before removing the AB electrodes from ground.

4) When operating in the Low-Res mode, there is no risk of electrical shock. However, in order to prevent battery short-circuits, it is recommended to first disconnect the mains cables from the battery terminals before removing the respective banana plugs from the equipment.

\section{CONCLUSION}

Our resistivimeter is easy to operate and was able to generate convincing results despite its simplicity. From a pedagogical viewpoint, it enables practical classes in electrical methods for Applied Geophysics students at a very low-cost. More generally, the use of such device improves the motivation of students taking courses that typically involve only theoretical content without any kind of associated field work. In interviews carried out with several students who took our Applied Geophysics class over the last three years, we observed a considerable increase in their interest spurred by the increased emphasis on the field techniques, computer programs and methodologies employed for resistivity data analyses. Moreover, the vast majority of students reported that carrying out the proposed field activities significantly facilitated their understanding of the core physical concepts that form the basis for electrical resistivity surveys and other related methods of Applied Geophysics.

We are currently developing a more sophisticated version of the device that will incorporate automated facilities to cancel the effects of natural currents and electrode potentials during the measurements. This equipment will also be capable of multi-electrode 
operation with built-in electronic switching and computerized data acquisition for 2-D and 3-D resistivity surveys.

\section{ACKNOWLEDGEMENTS}

The authors would thank the enterprise LTI Construções for providing the borehole logs used as a reference in this article.

\section{REFERENCES}

BHATTACHARYA PK \& PATRA HP. 1985. Direct Current Geoelectric Sounding. Elsevier, N. Y., 134 pp.

CUTRIM AO \& SHIRAIWA S. 2011. Prospecção de água subterrânea no sudoeste do município de Rondonópolis (MT) usando sondagem elétrica vertical. Brazilian Journal of Geophysics, 29(4): 745-751.

CUTRIM AO, RUIZ AS, LIPORONI LM, MEDEIROS FA, BARROSO UC \& NASCIMENTO AL. 2007. Sondagem elétrica vertical aplicada em pesquisa hidrogeológica na bacia do Parecis, MT. Brazilian Journal of Geophysics, 25(2): 131-140.

GEOTOMO SOFTWARE. 1995. 1-D Resistivity, IP and Modeling version 1.00.09 Beta, Freeware. Available on: <http://www.geotomosoft.com/downloads.php >. Access on: September 25, 2014.
LOKE MH. 1999. Electrical Imaging surveys for environmental and engineering studies - A practical guide to 2-D and 3-D surveys. Available on: <https://pangea.stanford.edu/research/groups/sfmf/docs/ DCResistivity_Notes2.pdf>. Access on: August 4, 2015.

LTI CONSTRUÇÕES. 2013. Perfis individuais de furo de sondagem a percussão, SPT-01 and SPT-02. Obra 014/13. Private communication.

NGUYEN F, GARAMBOIS S, JONGMANS D, PIRARDS E \& LOKE MH. 2005. Image processing of 2D resistivity data for imaging faults. J. Appl. Geophys., 57: 260-277.

RUCKER DF, LOKE MH, LEVITT MT \& NOONAN G. 2010. Electricalresistivity characterization of an industrial site using long electrodes. Geophysics, 75(4): WA95-WA104.

RUCKER DF, FINK JB \& LOKE MH. 2011. Environmental monitoring of leaks using time-lapsed long electrode electrical resistivity. J. Appl. Geophys., 74: 242-254.

XIAJ, LUDVIGSON G, MILLER RD, MAYER L \& HAJ A. 2010. Delineation of a volcanic ash body using electrical resistivity profiling. J. Geophys. Eng., 7: 267-276. 